\title{
ELEMENTS OF CHROMOSOME ABNORMALITIES
}

\author{
N. IslaM, B.Sc., M.B.B.S. \\ Department of Patho!ogy, Dudley Road Hospital, Birmingham
}

Over the past 60 years the science of cell genetics has made profound contributions to an understanding of the hereditary process. It was only seven years ago, however, that geneticists were able to establish the number of chromosomes in the human cell. These are the structures in the cell nucleus that encode the heredity plan. To look through the microscope at the chromosomes of man is to see the very stuff that human life is made of. The study of chromosomes can be said to have been started by Walter S. Sutton at Columbia University in 1903 and subsequent investigations by Thomas Hunt Morgan and A. H. Sturtevant showed that the units of heredity, the 'factor' of Gregor Mendel, must be arranged in linear order on the chromosomes.

These findings stimulated study of the chromosomes in various animals and plants. It was soon discovered that whereas the total number of chromosomes varies in different organisms, from two in some species of worm to 300 in certain protozoa, the number in the cell is constant in any species. It was a relatively simple matter to count the chromosomes of organisms, notably the fruitfly, in which they are large and few. Where they are small and numerous, however, the task was burdensome and different results were reported by different investigators. For example, J. H. Tjio and Albert Levan (1956) of the Institute of Genetics at Lund found that in the human cell the number of chromosomes was 46 and not 48 as had been previously believed.

\section{Chromosome Structure}

To understand the chromosome aberrations which occur in different conditions, we must have a basic knowledge of their normal structure and behaviour. Each cell, including the germ cells that give rise to sperms and ova, bears two sets of chromosomes. The 'homologous' chromosomes of each set (with the exception of the chromosomes which determine sex) are similar in appearance and carry genes affecting the same trait: one set is contributed by each parent. The 'somatic' or body cells divide by mitosis
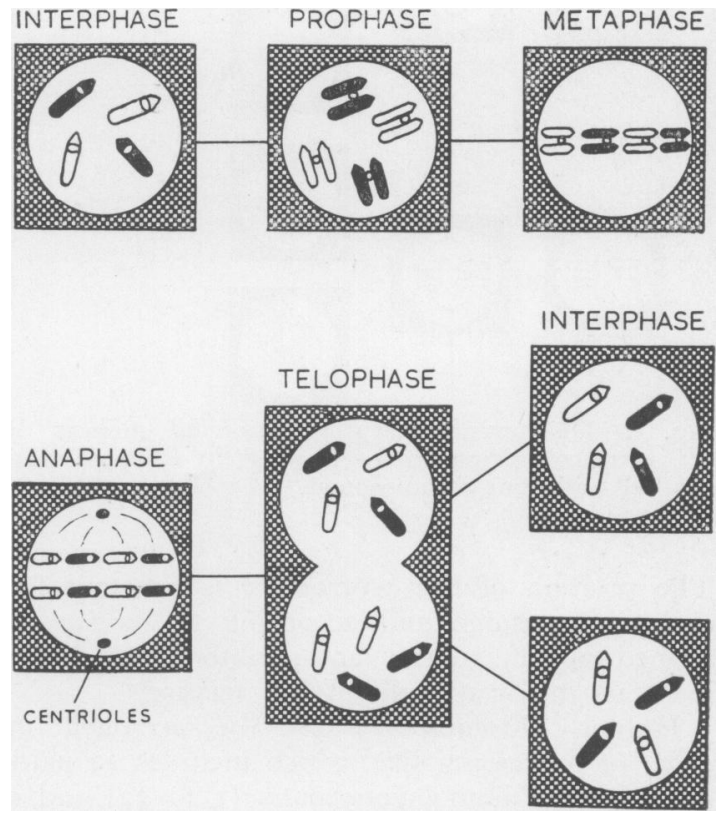

FIG. I.-Diagrammatic representation of mitosis in a hypothetical cell with four chromosomes.

so that each daughter cell has the same number of chromosomes as the mother cell (Fig. I). On the other hand the germ cell divides in a two-step process called meiosis, the chromosomes being duplicated only once before the first division. In the second division the two sets of chromosomes pull apart or segregate to produce sperm or ova (gametes) with only one set of chromosomes ('haploid'), in other words half the number of chromosomes of the precursor cells (Fig. 2). The subsequent union of the gametes produces a fertilized egg (zygote) with the full ('diploid') number of chromosomes. Each chromosome is a rod-shaped structure, split longitudinally into two chromatids which were destined to become the daughter chromosomes of the two new cells. The two chromatids are held together at a constricted region, the centromere, which does not take up any stain and looks like a vacuole. 


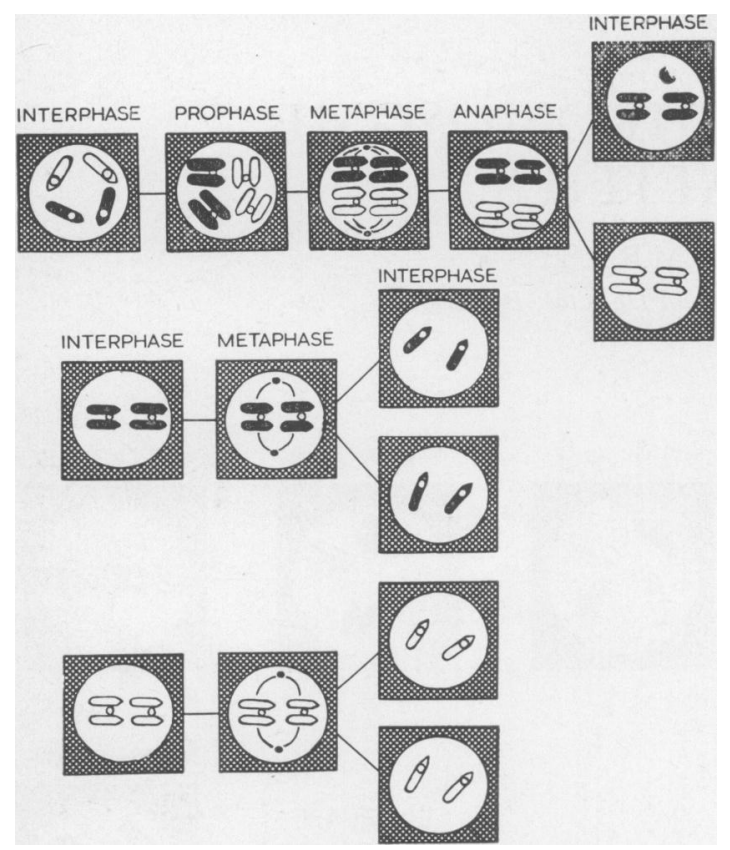

Fig. 2.-Diagrammatic representation of meiosis of germ cell giving rise to 'haploid' in a hypothetical cell with four chromosomes.

The position of the centromere is constant for each chromosome and according to its site is termed median, submedian or subterminal. Thus it is an important identifying feature.

Human chromosomes can be arranged in order of decreasing size, which includes 22 pairs of autosomal homologous pairs ( 1 to 22) and a pair of sex chromosomes of equal length in the female but of unequal length in the male (XX and $\mathrm{XY}$-Fig. 5). The longest chromosome is about 7-8 microns in length and the shortest about 1.5 microns. For identification they have been classified into groups according to their absolute lengths, their 'relative lengths' in relation to

Denver Nomenclature

\begin{tabular}{|c|c|c|c|}
\hline Group & $\begin{array}{c}\text { Size and Centromere } \\
\text { Position }\end{array}$ & $\begin{array}{l}\text { Idiogram } \\
\text { No. }\end{array}$ & $\begin{array}{l}\text { No. in Dip- } \\
\text { loid Cell. }\end{array}$ \\
\hline $\begin{array}{l}\text { (A) } \\
\text { (B) } \\
\text { (C) }\end{array}$ & $\begin{array}{cc}\text { Large, median } & \text { or } \\
\text { submedian } & \ldots \\
\text { Large, submedian } \ldots \\
\text { Medium, submedian }\end{array}$ & $\begin{array}{l}1-3 \\
4-6 \\
7-12 \& X\end{array}$ & $\begin{array}{c}6 \\
6 \\
\text { I } 3 \text { (male) or }\end{array}$ \\
\hline \multirow[t]{2}{*}{$\begin{array}{l}\text { (D) } \\
\text { (E) } \\
\text { (G) }\end{array}$} & $\begin{array}{l}\text { Medium } \\
\text { Small .. } \\
\text { Smallest, median } \\
\text { Small, subterminal }\end{array}$ & $\begin{array}{l}13-15 \\
16-18 \\
19-20 \\
21 \& 22 \& Y\end{array}$ & $\begin{array}{c}6 \\
6 \\
4 \\
5 \text { (male) or } \\
4 \text { (female) }\end{array}$ \\
\hline & & & 46 \\
\hline
\end{tabular}

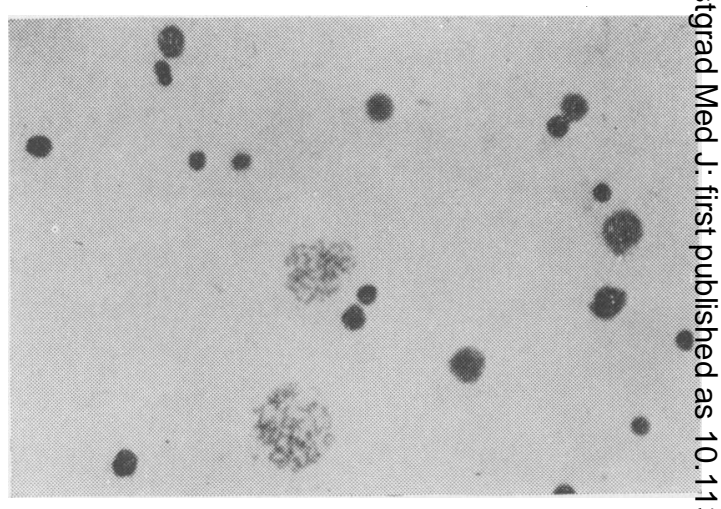

Fig. 3.-Photomicrograph of blood culture after treat $\bar{\omega}^{\bar{\omega}}$ ment with colchicine.

the total female diploid length (sum of the absolutis length and the length of the one $\mathrm{X}$ chromosomet and the arm ratio (ratio of the long arm to the length of the short arm) (Denver Nomerclature)

\section{Techniques}

옥

Chromosomes assume their most visible form at the metaphase of mitosis, when they are ready to separate. Colchicine has the unique property of stopping mitosis at this stage and has begefo utilized in the study of chromosomes.

There are three chief sources of mitosis whack have been utilized so far:

(I) Classical tissue culture methods, aimin at the production of a single layer of cells growing rapidly on a flat glas® surface. This gives good results, but is time-consuming and needs skill an labour.

(2) Marrow cell culture in tissue culture media? These two methods are still of great value but successive samples cannot be obtained withou considerable discomfort to the patient, and if long-term cultures it is sometimes difficult to avoid alteration in the chromosome complement?

(3) Blood is the most convenient tissue sample There is ordinarily no division in usuat tissue culture media, but by addin phytoagglutinin extract from Frence. kidney beans, culture can be obtainedy satisfactorily. The red cells are preciro pitated from a blood sample with th\& extract added and the white cells in cubated in the remaining plasma wit added synthetic tissue culture mediunt An unexplained burst of mitosis occurs about the third day. This method not only avoids unnecessary skin biopsy of sternal puncture, but gives better result and is almost universally used at presen 


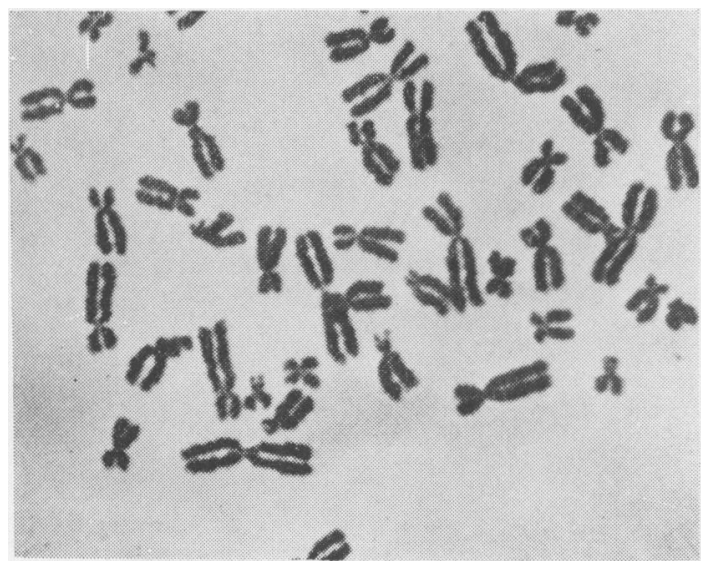

FIG. 4.-Photomicrograph of blood culture (white cell) after treatment with colchicine and hypnotic saline.

In the latter stages of all methods colchicine is added to stop mitosis at metaphase, when the chromosomes are ready for separation by the mitotic apparatus and have assumed their most visible form. It also breaks up the spindle and allows the chromosomes to separate, instead of lying bunched together in the familiar starshaped mass. This spreading process is helped by making the cells swell (just before fixation) with hypotonic solutions, and by flattening them out on the slide either by judicious squashing or by air-drying. The cells are stained and then examined under the oil immersion lens (Fig. 3-4). They may be analysed from a photographic print at a suitable enlargement $(\times 3,000-4,000)$ or from a camera lucida drawing. In order to exclude errors due to artefacts arising in these preparations, a number of mitotic cells (usually up to 100) are analysed. The chromosomes are first arranged in order of decreasing size and classified into groups according to the Denver classification. By this method accurate identification of at least six pairs of autosomes $(1,2,9,16$, 17 and I8) the Y chromosome and sometimes an additional four autosomal pairs (19, 20, 21 and 22) can reasonably be made. For more specific identification of the remaining pairs one must look for secondary constrictions and 'satellite' formations. (Fig. 5)

With the present degree of precision one can be sure of reliable identification of 14 of the 23 pairs at the most. A large proportion of the human chromosome abnormalities involve the sex chromosomes, which means that it is most important to be able to identify the $\mathrm{X}$ and $\mathrm{Y}$ chromosomes accurately in somatic cells. The $\mathrm{Y}$ chromosomes present no difficulty, although there is considerable variation in size in normal individuals; they are readily distinguished as
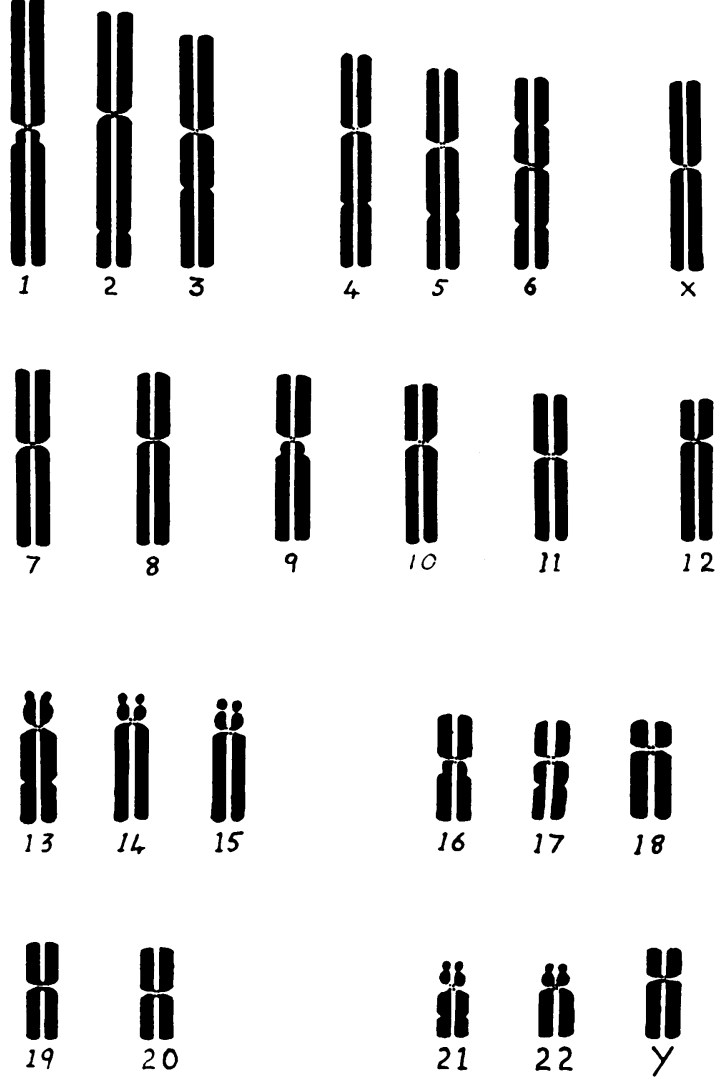

FIG. 5.-Diagram showing absolute and relative lengths of chromosomes with primary and secondary constrictions (one from each pair has been shown).

the largest of the smallest group of chromosomes with subterminal centromeres. Unfortunately the $\mathrm{X}$ chromosome is not so easily identified. It is generally the seventh largest chromosome, but may prove to be difficult to tell apart from the sixth and seventh pair of autosomes. In such a situation we rely very heavily on the nuclear sex diagnosis.

\section{Nuclear sex chromatin detection}

The sex chromatin body can be identified in $30-60 \%$ of cells in females. Vaginal smears stained with aniline dyes or differential stains give the best results, though buccal smears, sections of skin and white blood cells can also be used.

There is now considerable evidence to support the view that the sex chromatin is formed from at least part of one of the two $\mathrm{X}$ chromosomes in the female cell. It is not present in cells which carry only one $\mathrm{X}$ chromosome, as in XY (normal male) and XO (Turner's syndrome). In the Triple $\mathrm{X}$ syndrome (XXX) two sex chromatin 


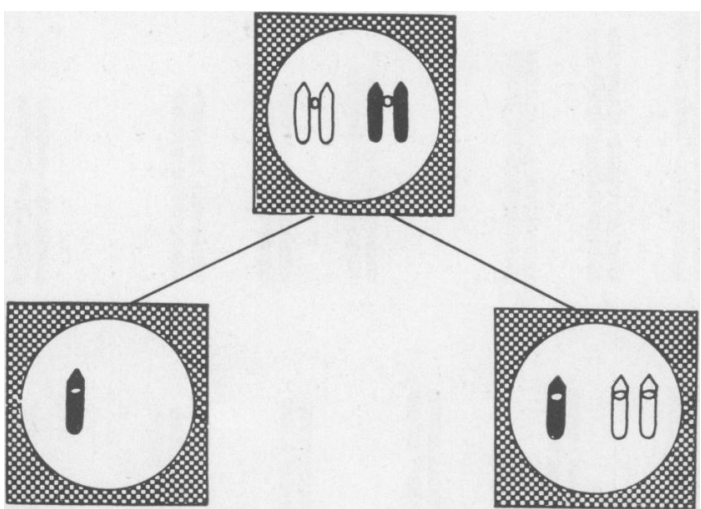

FIG. 6.-Diagrammatic representation of non-disjunction by means of which a cell can come to have the wrong number of chromosomes (shown in the case of one homologous pair of chromosomes).

bodies are present. The number of sex chromatin bodies increases with the number of $\mathrm{X}$ chromosomes.

These observations relate the sex chromatin directly to the sex chromosome constitution and thus make the nuclear sex diagnosis an exceedingly important aid to accurate chromosome analysis.

\section{CHROMOSOME ABNORMALITIES}

The chromosome abnormalities which can be recognised by present microscopic methods are fairly gross. The number is smaller still when we exclude lesions which are incompatible with survival.

Simple variation in count is, of course, the most easily identified anomaly. We can usually recognise the particular chromosome which is in excess or is missing. The number of such anomalies is finite in each species. A structural deformity of a chromosome can be identified only if it is relatively massive. We are able to distinguish loss of half a micron from the smallest chromosomes (say 22) because this is nearly half its long arm, but a much larger loss (say from I) may pass unnoticed.

\section{Aberration in number}

Loss or gain of the sex chromosomes seems to be especially well tolerated. Sex chromosome monosomy (a single X, XO in Turner's syndrome) is the only form of monosomy yet recognised, and nearly all the cases with more than one extra chromosome have involved the sex chromosomes. Loss, for instance, of one whole chromosome (monosomy) is always fatal in cases of autosomes. Gain of an extra chromosome is damaging, but several varieties at least are compatible with life and one even with reproduction.

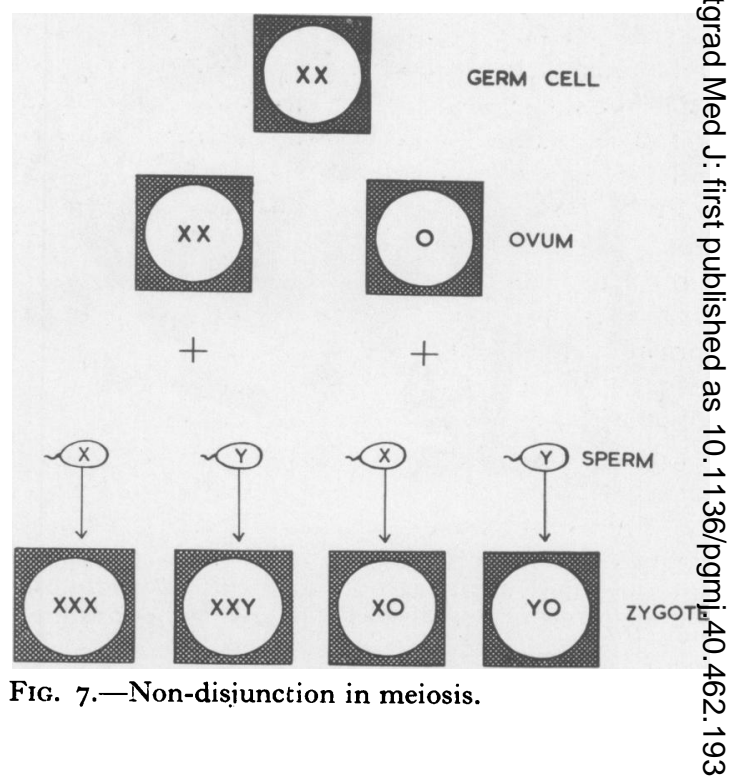

The mechanism by which an individual ce $\$$ might come to have an extra chromosome or lose one of its normal number is known as non disjunction (Fig. 6). In these rare condition ․ㅛ. two $\mathrm{X}$ chromosomes of a female germ cell fails to 'disjoin' in the first stage of meiosis. On\&్ㅇํㅇ the ova produced by the next division accordint receives both $\mathrm{X}$ chromosomes and the ot no $\mathrm{X}$ chromosomes. The same may happer in the case of male germ cells and auto somes. The most commonly affected autosome is $2 \mathrm{r}$. The ultimate cause of non-disjunction remains to be established, although over $\overrightarrow{\vec{\theta}}$ accumulation of some metabolic products in the ovum of the older woman or the activation of a 'latent' virus have been blamed.

\section{Clinical manifestations}

I. Sex Chromosomes. (Fig. 7)

(a) $X X X$ syndrome (Trisomy $X$; superfemale) This occurs in one in 1000 live female birth and in less than $1 \%$ institutionalized mentab cases. They are often fertile, producing normat offspring and are difficult to diagnose clinicallyo Vaginal and buccal mucosa show duplicated sex chromatin bodies. Cases with four X chromosomeo occur, but much more rarely. The abnormality is greater than with simple XXX. Buccal smearu shows the sex-chromatin body for each extra $X_{\sigma}^{\omega}$ chromosome-the total being one less than the number of $\mathrm{X}$-chromosomes in each case.

(b) $X X Y$ syndrome (Trisomy $X Y$; Klinefelter'\$ syndrome). This occurs once in about every 400 live male births and is characterized in adults by tallness, enlargement of the breasts, atroph $\vec{D}$ of the testicles and virtual non-production of 
sperms. It may be associated with mental defect and constitutes about $\mathbf{I} \%$ of institutionalized male mental cases. Such patients are sterile, and testicular biopsy shows tubular atrophy and Leydig cell hyperplasia. The sex chromatin body is present in buccal mucosa. Mosaicism may occur (see below).

(c) XO syndrome (Monosomy $X$; Turner's syndrome). These patients are female in appearance, although they lack many secondary sexual characteristics. They may also display congenital defects, such as unusually short stature, a 'webbed' neck, malformation of the aorta, deafness and mental deficiency. This is the only monosomy yet recognised. Clinical diagnosis is usually easy, at least after puberty. Sex chromatin body is absent in buccal mucosa, but mosaics with intermediate patterns may occur.

(d) A final possibility would be fertilization of an ovum with no $X$ chromosome by a Y-bearing sperm. This would produce a YO zygote, but such a chromosome complex is apparently incompatible with life-at least no such individuals have been recognised.

\section{Autosomes:}

(a) Trisomy $2 \mathrm{I}$ (Mongolism; Down's syndrome). They occur once in 600 live births and are congenital mental defectives. The cause is now demonstrated to be due to an extra chromosomeeither 21 or 22 , though conventionally taken to be $2 \mathrm{I}$-the total chromosome number being 47 . Statistically the risk of bearing a mongoloid child rises steeply with the age of the mother. A very few mongols have the normal number of 46 chromosomes and sometimes 45 chromosomes, but these are the 'translocation' cases, in which the bulk of the extra chromosome 2I is still present but attached to another chromosome (see below). The important practical application in relation to Down's syndrome is in predicting the chances of the parents having a second similarly affected child. It has recently been shown that this risk is higher than in the general population, and this is particularly the case with young mothers, for whom the general risk is low. Parents with detectable chromosomal abnormalities also have an increased risk of having an affected child. The most common such abnormality appears to be the possession by the mother of a translocated chromosome comprising the major part of 15 and 21 . Women with such an abnormality have a risk as high as $I$ in 3 of having a child with the syndrome at any individual pregnancy. Men with this translocation appear rarely to have affected children, though Down's syndrome may appear in their daughters' children. (b) Trisomy of Group E. The next most frequent and best established entity is due to an extra chromosome in the $16-18$ group, which is probably chromosome 18 . The syndrome includes mental defect, low-set malformed ears, micrognathia, flexion deformities of the fingers and congenital heart disease (V.S.D.). The syndrome can be diagnosed clinically by experienced clinicians.

(c) Trisomy of Group D. An extra chromosome in the I3-I5 group has been found on several occasions. The syndrome includes eye defects (anophthalmia or colobomata), hare-lip, cleft palate, polydactyly and congenital heart disease.

Trisomy of Group F (19-20) and of 22 have been reported, but none have been conclusively differentiated as regards their individual clinical status. Autosomal trisomy, however, may be entirely asymptomatic. Chromosomal defects involving large autosomes (Group $\mathrm{A}-\mathrm{B}$ ) are extremely rare.

\section{Alterations in structure}

The number of aberrations in the structure of chromosomes is infinite. The two principle types are deletions and translocations. In deletions part of a chromosome breaks off and is lost. Such abnormalities, particularly if they involve sizeable amounts of the genetic material, could be expected to be lethal in many cases, and large deletions are in fact not commonly found.

In translocation, breakage is followed by relocation of the fragments. A reciprocal translocation involves breaks in two nonhomologous chromosomes and thereafter a mutual exchange of the fragments. Depending on how the chromosomes behave during meiosis, some gametes will be found with a normal, although displaced, gene content, i.e. a balanced translocation. But translocation may also give rise to gametes that have deficiencies of certain genes and duplications of others. Some offspring of gametes that carry translocations may, therefore, be normal and some may not. The germ cells of an apparently normal person who bears a balanced translocation may undergo meiosis in such a way that occasional members of the family acquire an extra $2 \mathrm{I}$ and so appear as mongols, thus giving rise to the most important variety (even if rare) of familial mongolism.

\section{Clinical manifestation}

(I) The first recognizable translocation was found in 1959 in a mentally deficient boy with associated abnormalities of the spine. The cells had only 45 chromosomes including one that was longer than its homologue. It was suggested that part of the missing chromosome had been 
relocated, thus explaining the extra length of the abnormal chromosome, the remaining fragment being eliminated.

(2) Recent reports that some patients suffering from Down's syndrome have a normal number of 46 and others 45 chromosomes may be explained by translocation. In these cases the extra material, usually present as an extra 'free' chromosome (trisomy of chromosome $2 \mathrm{I}$ ) is translocated to another chromosome or a chromosome has been deleted. The disease would seem, therefore, to be related not so much to the number of chromosomes in the cells as to the extra chromosomal material.

(3) Patients with chronic myelogenous leukæmia have what appears to be a unique chromosomal aberration: deletion of a small part of one of the smallest chromosomes tentatively identified as 2.I, the same as that associated with Down's syndrome (Philadelphia chromosome). The association of abnormal white cell formation with chromosome $2 \mathrm{I}$ is strengthened by the fact that acute leukæmia is many times more common in patients with Down's syndrome than in the general population. Malignant cells frequently have abnormal chromosomes of various types. So far the abnormalities in cancer cells have given little help in diagnosis except in chronic myeloid leukæmia. In this case the presence of 'ph-chromosome' is an almost constant feature in cultures of leucocytes from the peripheral blood and marrow. So this chromosome anomaly of the myeloid series is a useful guide for diagnosis and the course of treatment in this condition.

\section{Mosaicism}

The term mosaicism, in cytogenic usage, describes a condition in which a substantial minority of cells differ from the majority in their chromosomal content. In man the condition was first described in Klinefelter's syndrome and it has been reported in several other conditions involving the sex chromosomes, and also in mongolism. It was anticipated that hermaphrodites might turn out to be 'mosaics', some of whose cells are $\mathrm{XX}$ and some $\mathrm{XY}$. In nearly all instances, however, examination of the cells of hermaphrodites has disclosed 46 chromosomes and the XX constitution characteristic of a normal female.

It is none-the-less clear that human mosaics do occur; they are the products of non-disjunction, not in meiosis of parent germ cells but in mitosis of the somatic cells at some point in embryonic development soon after fertilization. Mosaicism is after all a statistical concept, since cell division can go awry at any time and resuctit in cells with the wrong complement of chrom $\bar{z}$ somes. Presumably these cells are usually at disadvantage and are eliminated. Nevertheless, there may be a small number of aberrant cells in every normal individual.

\section{Comments}

The identification of constitutional defec

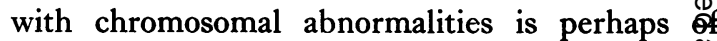
more direct interest to medicine than to geneticos. Many fundamental genetic studies of the cels of other organisms with fewer and larger chromosomes will continue to serve investigators better than human cells, but the questions relatiog specifically to man can only be settled by the study of his cells.

The present methods of studying chromosome are crude. We do not yet know the structupe of chromosomes and there is need for higher magnification in microscopic studies. There no known way of producing meiosis artificially which might help with pairing-off problems. Ovarian meiosis is hardly ever accessible in man and, though testicular biopsy is a simple enough procedure, a large proportion of the most interest ing examples have disorders of spermatogenesps which make it valueless. Even given an active testicular biopsy, the technical problemso of obtaining a preparation comparable to mode角 mitotic culture have not yet been overcome.

Present techniques are unable to demonstra the genetic lesions of traditional Mendel-inherited disorders like hæmophilia or phenylketonurie. These probably depend on a disorder of the desoxyribonucleic acid chain, perhaps the mist placement of a single base in the chain. Auteradiography of human cells after they have bee्दु supplied with radioactive nucleic acids shows that different segments of the chromosomes replicate at different times. By studying the pattern and significance of the sequence of ro plication we may one day be able to explain the alteration in the DNA chain which directs the nature and activity of cells. Long-term tissu cultures of cells, in which the chromoson complement has been altered, could be studied for the biochemical consequence of such changes. In this way it might be possible to determine which chromosome directs the synthesis off which enzyme and so obtain a clue to the main defects in inherited diseases.

I am grateful to Dr. A. Paton, Consultant Physician Dudley Road Hospital, for his guidance, encouragement, and valuable suggestions in preparing this paper.

I would also like to give thanks to Mrs. M. K. Mas\& for her secretarial assistance. 


\section{FURTHER READING}

Atrins, L. and Rosenthal, M. K. (1961): Multiple Congenital Abnormalities Associated with Chromosomal Trisomy, New Engl. F. Med., 265, 314.

Baikie, A. G., Buckton, K. E., Court Brown, W. M. and Harden, D. G. (I96I): Two Cases of Leukæmia and a Case of Sex Chromosome Abnormality in the Sibling, Lancet, ii, 1003.

Bearon, A. G. and German, III, J. L. (I961): Chromosomes and Disease, Scientific Amer., Nov., 66.

CARR, D. H. (1963): Chromosomal Abnormalities and Their Relation to Disease, Canad. med. Ass. F., 88, 456.

EGGEN, R. R. (1963): Review of Recent Advances in a New Field of Clinical Pathology, Amer. F. clin. Path., 39, 3.

Ferguson-Smith, M. A. (1962): Chromosome Abnormalities, Proc. roy. Soc. Med., 55, 47 r.

Guard, H. R. (1959): A New Technique for Differential Staining of the Sex Chromatin and the Determination of its Incidence in Exfoliated Vaginal Epithelial Cells, Amer. Y. clin. Path., 32, 145.

Herndon, C. N. Basic Contributions to Medicine by Research in Genetics, f. Amer. med. Ass., 177, 695.

LeNNOX, B. (196I): Chromosomes for Beginners, Lancet, i, 1046.

Spriggs, A. I., Boddington, M. M. and Clarkr, C. M. Chromosomes of Human Cancer Cells, Brit. med. F., ii, I43I 